Hispania Sacra, LXII

125, enero-junio 2010, 27-42, ISSN: 0018-215-X

\title{
LA CONTINUIDAD DE LA MENTALIDAD MEDIEVAL EUROPEA EN LA MISIÓN DE JAPÓN -EN TORNO A LA POLÍTICA DE EVANGELIZACIÓN-
}

POR

OSAMI TAKIZAWA

Universidad de Salamanca

\section{RESUMEN}

$\mathrm{Al}$ analizar los documentos de los jesuitas que trabajaron en evangelización que pusieron en marcha Francisco Javier y los jesuitas que continuaron su misión. Primero, los jesuitas procuraron bautizar a los señores feudales, como vía que allanaba el camino a la conversión de sus vasallos. Segundo, los jesuitas intentaron extender el cristianismo entre los bonzos e intelectuales y después en el pueblo llano. Cabe preguntarse si los métodos utilizados presentan similitudes con la evangelización en la Edad Media en Europa, si los europeos aplicaron estos métodos medievales en la sociedad japonesa. El objeto de este artículo es analizar estas cuestiones.

PALABRAS ClAVE: Misión de Japón, jesuitas

\section{THE CONTINUITY OF THE EUROPEAN MEDIEVAL MENTALITY IN THE MISSION OF JAPAN -NOTES ON THE POLICY OF EVANGELIZATION_-}

\begin{abstract}
From the analysis of the documents of the Jesuits who worked in Japan between the XVI and XVII centuries, we can note the methods of evangelization put into practice by Francisco Javier and the Jesuits who followed his mission. Firstly, the Jesuits aimed at baptizing the feudal lord as a way that eased the path to the conversion of their respective vassals. Secondly, the Jesuits tried to extend the Christianism among monks and intellectuals and thereafter among the common people. It can be questioned if the methods used showed any similarity with the evangelization in the Medieval Time in Europe, if the Europeans applied
\end{abstract}


such Medieval methods in the Japanese society. The purpose of this article is to analyse these questions.

KEY WORDS: Mission of Japan, Jesuits

Recibido/Received 19-02-2009

Aceptado/Accepted 14-12-2009

En España se está investigando sobre la continuidad de la mentalidad medieval en las misiones cristianas. Un ejemplo es la obra de Luis Anselmo Duarte Duarte, «Ideales de la Misión Medieval en la Conquista de América». ${ }^{1}$ Pero, aún faltan investigaciones sobre la misión de los jesuitas en el Japón y la influencia que en ella tuvo la mentalidad medieval europea. Por este motivo, comencé a investigar este tema bajo la dirección de Miguel Ángel Ladero Quesada, de la Real Academia de la Historia.

$\mathrm{Al}$ analizar los documentos de los jesuitas que trabajaron en Japón en los siglos XVI y XVII podemos descubrir los métodos de evangelización de Francisco Javier y de los jesuitas que continuaron su misión. Los jesuitas procuraron bautizar a los señores feudales, como vía que allanaba el camino a la conversión de sus vasallos. Los jesuitas intentaron luego extender el cristianismo entre los bonzos e intelectuales y después en el pueblo llano.

Cabe preguntarse si los métodos utilizados presentan similitudes con la evangelización en la Edad Media en Europa, si los europeos aplicaron estos métodos medievales en la sociedad japonesa. El objeto de este artículo es analizar estas cuestiones.

Desde que Francisco Javier comenzara la evangelización del Japón en 1549, el cristianismo fue extendiéndose gradualmente por todo el archipiélago. A través de la conversión de los señores feudales, los samurais y el pueblo llano, el cristianismo arraigó profundamente. Se afirma que en el año 1582 había ya más de 150.000 cristianos en Japón. Sin embargo, desde 1587 el gobierno de Japón, con Toyotomi Hideyoshi a la cabeza, comenzó una política de dura persecución del cristianismo, propiciada por el miedo a perder el dominio de la nación. Luego, en 1612 en la Edad de Edo se publicó la Orden de Prohibición del Cristianismo en Japón. Así, comenzó la época de la gran persecución contra los cristianos. Durante ella el profundo arraigo de la Iglesia católica se manifestó en el elevado número de mártires que se hubo. Por fin, en 1616, el shōgunato (el gobierno de Tokugawa) promulgó la política de aislamiento que se prolongará hasta el siglo XIX.²

\footnotetext{
${ }^{1}$ Luis Anselmo Duarte DuARte, Ideales de la Misión Medieval en la Conquista de América, Fundación Universitaria Española, Madrid, 2001.

${ }^{2}$ Cfr. Osami Takizawa, Tradiciones Medievales y Nuevos Elementos en la Misión del Japón. Primeros Contactos Culturales entre Japón y España. Siglos XVI-XVII, Tesis doctoral, Universidad Complutense de Madrid, Madrid, 2007, capítulo I., pp. 65-81.

Hispania Sacra, LXII

125, enero-junio 2010, 27-42, ISSN: 0018-215-X
} 
EL MÉTODO DE EVANGELIZACIÓN DESDE ARRIBA HACIA ABAJO

La evangelización se hace desde los señores feudales hasta el pueblo. Podemos tener presente la investigación del Prof. José Orlandis plasmada en su trabajo «La Conversión de Europa al Cristianismo» que sirve de punto de apoyo en nuestro análisis. Para Orlandis, en la Europa Medieval los misioneros primero bautizaban a los señores feudales, y luego a sus vasallos. Profundiza en la historia de la conversión del rey de los Francos, Clodoveo. En el proceso del establecimiento del imperio franco (486) Clodoveo tuvo que luchar con otra tribu. Clotilde, su esposa era cristiana. Había recomendado siempre a Clodoveo su conversión al cristianismo. Así, después de su victoria en 496, el Rey fue bautizado con 4.000 vasallos. Pasó a ser protector de la Iglesia Romana. ${ }^{3}$ Los misioneros adaptaron el mismo método en otros países europeos. Así encontramos los casos de la conversión de Recaredo en España, el bautismo del duque Mieszko en Polonia o el del príncipe san Vladimiro en Rusia. ${ }^{4}$

Los jesuitas introdujeron este método en la evangelización del Japón. Para una mejor comprensión de esta metodología, analizaremos primero la sociedad japonesa, sobre todo, el feudalismo y los estamentos sociales en la época en que tuvo lugar la evangelización del Japón, coincidente con su tránsito desde la Edad Media hasta la Moderna. Puede decirse que en este período la sociedad japonesa se caracteriza por el predominio de los Samurais. Su origen en Japón se remonta a finales de la Edad de Heian. Los emperadores japoneses organizaron algunas fuerzas para defender la Corte en Kioto. Originalmente, los descendientes de los emperadores de Seiwa y de Kanmu comenzaron a dedicarse a servir como guardia de la Corte. Se empezó por denominarles «Samurao», «Bushi», que significaba «los hombres que se dedicaban a la guerra». Cada miembro de ese grupo era un Samurai. Pronto se organizaron en dos grandes grupos: los descendientes del emperador Seiwa llamados Genji y los del emperador Kanmu, denominados Heishi. ${ }^{5}$

Mientras tanto, en el siglo X, los señores feudales surgidos del régimen político imperial, acumularon mucho poder y poseyeron grandes latifundios. La mayoría de ellos pertenecían al clan Fujiwara y su origen se entronca con la familia imperial. En la administración de estos grandes latifundios señoriales algunos terratenientes se convirtieron en clanes armados. Algunos de éstos se transformaron posteriormente en samurais. En los conflictos entre los dueños de los latifundios, tuvo gran relieve la actuación de los samurais. En este contexto los emperadores y la nobleza de Kioto supieron valorar su importancia. ${ }^{6}$

\footnotetext{
3 José ORLAndis, La Conversión de Europa al Cristianismo, Rialp, Madrid, 1988. P. 71-73.

${ }^{4}$ Ibidem, p. 100.

5 Susumu IsHII, Historia de Japón, Yamakawa, Tokio, 1996, pp. 79-81.

${ }^{6}$ Ibidem, p. 79.
} 
En 1156 y en 1159 hubo dos grandes rebeliones en Japón en torno a la división de la familia imperial (la de Hougen y la de Heiji). ${ }^{7}$ Al acabar, la fuerza política y social de los samurais superó a las tropas de la familia imperial. El jefe del clan de Heishi, Taira no Kiyomori, el triunfador en el conflicto, ascendió a primer ministro del gobierno. Taira no Kiyomori llevó a los miembros de su familia a los puestos más altos. Así el régimen político imperial existente fue sustituido por el de los samurais. ${ }^{8}$ Sin embargo, los dos grandes clanes -Genji y Heishi- comenzaron a oponerse entre ellos para conseguir la hegemonía. De ese modo empezó la batalla de Genpei que implicó a todos los Samurais del país. Finalmente, en marzo de 1185 el clan de Genji ganó la batalla. En 1192 Minanoto no Yoritomo, jefe del clan de Genji fundó su gobierno en la ciudad de Kamakura, y adquirió el título de shōgun. ${ }^{9}$

Desde este momento, comenzó el régimen de los samurais. Bajo él, se formó el feudalismo japonés. Los señores feudales concedían tierras a sus vasallos como merced (Goon) y éstos servían a sus señores en caso de guerra (Hōkō). Básicamente, el tipo del feudalismo japonés tenía muchas semejanzas al europeo. ${ }^{10}$ Hasta finales del siglo XVI no se consolidaron los señoríos. Por eso, los señores feudales de distintos lugares continuaron guerreando para conseguir su hegemonía. ${ }^{11}$ Cuando los jesuitas llegaron a Japón, había dos grandes señores feudales: Oda Nobunaga ${ }^{12}$ y Toyotomi Hideyoshi, que intentaron unificar todos los territorios. Por fin, en 1590 Toyotomi Hideyoshi se alzó con la victoria. Durante su gobierno, se estableció una rígida división entre dos clases sociales: los samurais y los agricultores. ${ }^{13}$

Se puede observar un gran cambio de los estamentos sociales en el período de Toyotomi Hideyoshi. En 1588 Toyotomi Hideyoshi publicó una ordenanza denominada «Katanagari» que significaba literalmente «quitar las espadas». Tras esta orden, ejecutó una política de separación estricta entre los soldados Samurais y los agricultores, prohibiendo a estos últimos la posesión de espadas y armaduras. En 1591 publicó la ordenanza de regulación de los estamentos sociales llamada Hitoharairei. En esta orden estableció que los servidores de los Samurais no podían hacerse ni ciudadanos, ni agricultores. Asimismo prohibió que los agricultores se dedicaran al comercio. Además, en 1592 llevó a cabo diversos censos para averiguar el número de familias existentes y el de sus componentes, estableciendo una división de las clases sociales en tres: los Samu-

\footnotetext{
${ }^{7}$ Ibidem, pp. 84-85.

8 Ibidem, pp. 85-87.

${ }^{9}$ Ibidem, pp. 90-91.

10 Ibidem, pp. 93-94.

${ }^{11}$ Ibidem, pp. 129-131.

12 Ibidem, pp. 152-154

13 Ibidem, pp. 154-155.
} 
rais, los ciudadanos y los agricultores. Tras estas ordenanzas, buscó el control de las clases sociales. ${ }^{14}$

Después de la muerte de Toyotomi Hideyoshi, en 1600, hubo una gran batalla llamada Sekigahara no Kassen. El triunfador de esta batalla, Tokugawa Ieyasu, estableció su shōgunato en la ciudad de Edo. Así, empezó el período de Edo que continuaría hasta el año 1867. Bajo el régimen de Tokugawa, se estableció el absolutismo. El gobierno controló a todos los señores feudales y sus territorios. En esta época por contra el emperador se transformó en un símbolo que no podía ejercer el poder político. ${ }^{15}$

En el período de Edo hubo grandes cambios en la estructura de los estamentos sociales. El shōgunato estableció cuatro clases principales; Samurais, agricultores, artesanos y comerciantes. Los dominadores eran los samurais, el emperador y familia imperial, los monjes budistas y sintoístas. Especialmente, los samurais ocuparon la política y el ejército, y se les concedieron diversos privilegios, incluido el de llevar armas y conservar sus apellidos. El resto de las clases sociales, los agricultores, los artesanos y los comerciantes, se encontraba sometido. Los Samurais eran aproximadamente el 5 por ciento y los agricultores, el 80 por ciento del país. Este orden social apenas sufrió cambio alguno hasta finales del período de Edo. ${ }^{16}$

Por otro lado, al igual que en los países europeos en Japón también hubo los Samurais las reglas de caballería, denominada Bushidō. La palabra Bushidō significaba «el camino que los Samurai debían conocer». Por tanto, Bushidō era la filosofía y la moral o la ética que los Samurai debían que respetar. No era una ley escrita, sino un conjunto de reglamentos y tradiciones que se transmitían de generación en generación. La caballería japonesa se fue formando paulatinamente desde el período de Kamakura hasta finales del Edo. Esa filosofía estaba imbuida del budismo, el sintoísmo y el confucianismo. ${ }^{17}$

Los Samurais respetaban esos principios morales, sobre todo en la relación existente entre los Señores y sus vasallos. La profundización de estos principios llegó al máximo rigor con el establecimiento del Harakiri o Seppuku. Cuando los Samurai no eran fieles a esos principios debían hacerse el harakiri, esto es, abrirse el vientre con una de sus espadas (Wakizashi), suicidándose para limpiar su honor. ${ }^{18}$

En 1551 el jesuita Cosme de Torres relató la vinculación entre los señores y sus vasallos en los siguientes términos: «Los criados y los esclavos respetan

\footnotetext{
${ }^{14}$ Masamoto KitAJIMA, Nihonshi Gaisetsu II, Iwanami, 1968, p. 28.

${ }^{15}$ Susumu IsHII, Historia de Japón, Yamakawa, Tokio, 1996, pp. 163-167, 169-172.

${ }^{16}$ Ibidem, pp. 173-174.

${ }^{17}$ Inazô NIToBe, Bushidô, Kôdansha, Tokio, 1998, pp. 28-57.

18 Ibidem, pp. 214-223.
} 
y sirven mucho a los señores feudales. Porque si cualquier señores notan la infidelidad de los vasallos, van a matarlos. Por eso, los vasallos siempre muestran sus obediencias a sus señores. Siempre los vasallos hablan con sus señores tocando sus cabezas sobre el suelo». ${ }^{19}$

\section{LOS JESUITAS Y LOS ESTAMENTOS SOCIALES JAPONESES}

Antes del comienzo de la evangelización, el jesuita Francisco Javier tuvo conocimiento de los estamentos sociales a través de las narraciones de su ayudante Anjirō:

«Primeramente [Anjirō] dijo que la longitud de la isla de Japón era 600 leguas, se dominaba todo la isla por un rey. Y dijo que debajo de él había otros señores como manera de duque».20

«El rey principal se llama Vo en su lengua, su casta es el más alto que otros. Esta casta no casa con otras. Parece que entre ellos Vo [Emperador] es como Papa. Tiene jurisdicción para los laicos y para los clérigos.....Goxo [Shōgun] que tiene mando y dominio sobre Japón ........21

«También [Anjirō] dijo que hay otros muchos señores feudales pequeños como condes, y hay otros señores en los señoríos territoriales. Dentro de éstos, hay hidalgos, comerciantes, artesanos que fabrican todas las cosas (como nuestros artesanos). Igual que en nuestra sociedad hay diferencias de los ordenes sociales.......22

El período al que se refiere es el de Oda Nobunaga. Así pues, los jesuitas conocían que en Japón existían el emperador, el jefe militar del Shōgun, los caballeros, los comerciantes y los artesanos. Pero, todavía sus observaciones eran imprecisas.

Un sucesor de Francisco Javier, Gaspar Vilela, dio cuenta en una carta fechada el 15 de septiembre de 1565, de los estamentos sociales japoneses.

«En esta tierra hay tres o cuatro clases de la gente: la primera es los hidalgos y gente noble que son ociosos debido a las guerras que ocurren continuadamente, la segunda es muchos comerciante que sostienen las vidas de la nación. La tercera son sacerdotes que sus números son iguales que la gente popular. La cuarta son labradores. Non tienen sus propias tierras, y cultivan las tierras de sus señores».23

19 «Carta de Cosme de Torres (29-Septiembre-1551)», Universidad de Tokio, Kaigai Nihon Shiryō II, pp. 17-18.

20 «Carta de Anjirō a Ingacio de Loyola en Roma», Universidad de Tokio, Nihonkankei Kaigaishiryō I, 1990, Tokio, página 36.

21 Ibidem, página 36.

22 Ibidem, página 38.

23 «Carta del Padre Gaspar Vilela escrito en Sakai a los Padres de convento de Avis en Portugal (15 de septiembre de 1565)». Murakami Nojirō, Yasokaishi Nihon Tsūshin, Shūfōaku, 1966, Tokio, p. 313.

Hispania Sacra, LXII

125, enero-junio 2010, 27-42, ISSN: 0018-215-X 
Observa que los estamentos sociales del período de Oda Nobunaga se componían por los hidalgos, los comerciantes, los sacerdotes y los labradores, pero su opinión todavía es confusa y poco detallada. Su análisis estaba influido por el concepto de las clases sociales occidentales de la Edad Media: Nobles, Clérigos y Trabajadores. ${ }^{24}$

Alejandro Valignano, Padre Visitador jesuita, escribe:

«Está todo Japón repartido en diversas suertes de gente. La primera es de los señores que llaman tono, que son los que mandan y señorean la tierra... La segunda suerte de gente es de los religiosos que llaman bonzos, que son muchos en número y poderosos... La tercera suerte de gente es de los soldados, que llaman buke, y son los caballeros y hidalgos honrados de la tierra. La cuarta es de mercaderes y otros oficiales que con su industria de comprar y vender y hacer otros oficios y artes mecánicas. La última es de la gente más baja, labradores y de servicio, que hacen en casa y fuera de ella todos los ministerios más bajos, de los cuales hay mucho más que en nuestra tierra». ${ }^{25}$

Se refiere a la familia de los samurais. Explicaba que además de ella, existía un emperador que dominaba el Japón controlando todo. ${ }^{26}$

En el período de Toyotomi Hideysohi, los jesuitas comprendieron ya de modo más claro los distintos estamentos: los señores feudales, los clérigos, los samurais, los comerciantes, los artesanos y los labradores. Alejandro Valignano entendió más exactamente la dualidad de la política japonesa formada por el emperador y el shōgun. En este análisis, se observa que se basaba en el concepto de estamentos sociales europeos formados desde la Edad Media hasta la Moderna: rey, nobleza, clérigos y ciudadanos.

El Padre jesuita Pedro Morejón analizó la familia imperial y los Samurais desde el período de Toyotomi Hideyoshi hasta el de Edo:

«Hablando pues con propiedades, y rigor, ni ay, ni huvo en Iapon muchos reynos, mas que uno solo desta familia, al qual llaman Vo, o Teivo, y Tenno, y tambien Dairi, aunque este es propio nombre de palacio, mas por ser mas comun, usaremos el en su modo de gobierno vestidos, ceremonias, y letras, procuran imitar el gobierno antiguo de la China; $y$ assi, tienen la nobleza repartida en dos ordenes, que llaman $\underline{\text { Cungue, }}$ y Buque. El gobierno antiguo era todo de los Cungue. Ellos eran los grandes de reyno, y los oficiales de la casa real. Sus consejeros, y los bovernavan los reynos en nombre del Dairi, con varios titulos, como entre nosotros de Duques, Marqueses; los quales titulos, y los oficios de la casa real, son ciento. Los mayores eran unicos y los demas los podian tener muchos. La mayor dignidad es Daije, Daijin, que es como ayo, o maestro del rey, y reyno. Y entre Romanos ser Padre de la Patria. El officio mayor es el de Quanbacu, que es como cancellario, que da las

\footnotetext{
24 José Luis Martín, Historia de España, ed. Espasa, Madrid, 2004, Vol. 4, p. 394.

25 Alejandro Valignano, Sumario de las Cosas de Japón (1583), Universidad Sofía, Tokio, 1954, p. 9.

${ }^{26}$ Ibidem, p. 100.
} 
dignidades, en nombre del rey. Esta orden sola de los Cungues, o Senadores, es la que puede tratar inmediatamente, y vezes ver al rey, o Dairi, todos ellos tienen sus insignas, vetidos, y lugares determinados, sin poder pasar un paso del lugar, o sala señalada, y sobre esto ay grande ambicion, y pretensiones, aunque mucho mas huvo antiguamente». ${ }^{27}$

Pedro Morejón emplea varios términos japoneses. Podemos concluir en el período de Edo se perfeccionó la idea de los jesuitas sobre los distintos estamentos sociales existentes en el Japón de la época.

\section{CONVERSIÓN DE LOS SEÑORES FEUDALES JAPONESES}

Desde el año 1563 hasta el período de Edo varios señores feudales japoneses se convirtieron al cristianismo. A estos señores conversos se les conocía como los «Señores Feudales Cristianos» (Kirishitan Daimyō). Se estima que más que veinte familias poderosas abrazaron el cristianismo. El primer señor feudal era Omura Sumitada.

A medida que se extendía el cristianismo en Japón hacia finales del siglo XVI, muchos señores feudales fueron convirtiéndose, sobre todo en la zona de Kyūshū y en la de Kinki (alrededores de Kioto). Así, cabe citar, entre ellos, a Ōtomo Yoshishige (Sōrin) (1530-87), Ōmura Sumitada (1533-87), Arima Harinobu (1567-1612), Kuroda Yoshitaka (1568-1623), ${ }^{28}$ Konishi Yukukinaga (?$1600)^{29}$ y a Takayama Ukon (1552-1614).

En la zona de Kyūshū, en el 1563 se produjo la conversión al cristianismo de Ōmura Sumitada. Éste prometió al Padre Gaspar Coello, Vice-Provincial para Japón durante los años 1581-1590, que recomendaría la conversión a sus vasallos y a los principales bonzos. En su dominio, desde 1576 hasta 1579, se bautizaron unas 35.000 personas. El 8 de abril de 1576 el señor feudal de Shimabara Arima Harinobu se hizo cristiano. Según una carta del Padre Alfonso Gonzalves, hasta octubre de ese mismo año, más de 20.000 personas fueron bautizadas en su señorío. El 28 de agosto de 1578 tuvo lugar la conversión del señor feudal de Bungo Ôtomo Yoshishige. Este señor recibió como nombre de

27 Pedro Molejón, Historia y Relación de los Sucedido en los Reinos de Japón y China, en la cual se continúa la gran persecución que ha habido en aquella Iglesia desde el año de 1615 hasta el de 1619. B. N. M. Impreso. R-31583. (Lisboa, 1621). p. 60v.

${ }^{28}$ Kuroda Yoshitaka era un señor feudal que tenía 120.000 demarcaciones (goku) en el territorio Buzen en la parte noreste de Kyûshû. Sirvó a Odanobunaga y al Toyotomi Hideyoshi. En la batalla de Sekigahara apoyó a Tokugawa Ieyasu.

${ }^{29}$ Konishi Yukunaga era un vasallo importante de Toyotomi Hideyoshi. Fueron destacadas sus hazañas en la expedición a Corea planeada por Hideyoshi. Fue ejecutado tras su derrota en la batalla de Sekigahara.

Hispania Sacra, LXII

125, enero-junio 2010, 27-42, ISSN: 0018-215-X 
bautismo Francisco en recuerdo de la figura de Francisco Javier. Hacia 1579 más de 10.000 personas habían sido bautizadas.

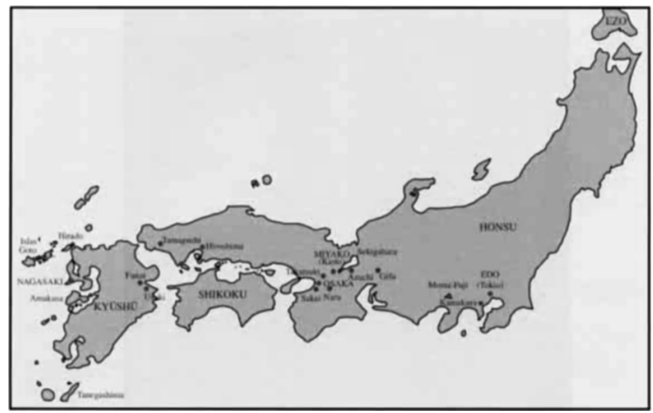

Mapa de Japón (S. XVI) ${ }^{30}$

En la zona de Kinki, gracias a la actitud favorable de Oda Nobunaga hacia los religiosos cristianos y a los buenos servicios que le prestaron los grandes samurais cristianos, en 1577 se convirtieron 8.000 personas. ${ }^{31}$ En Kinki, en 1564 el señor feudal Takayama Ukon fue bautizado por Lorenzo, y en 1560 se convirtió Konishi Yukinaga, entre otros. ${ }^{32}$ En principio la postura de los señores cristianos era muy benigna hacia sus vasallos conversos, pues admitían la libertad religiosa en sus dominios. Sin embargo, a medida que estos señores alcanzaban una mayor seguridad en su fe, abandonaban esta tolerancia y obligaban a sus vasallos a la conversión para oponerse con fuerza al poder tradicional de los budistas. ${ }^{33}$

$\mathrm{Al}$ leer los documentos de los jesuitas, entendemos cómo los súbditos y los pueblos de los señores feudales cristianos fueron convirtiéndose al cristianismo a raíz del bautismo de sus señores. En 1595 el jesuita Organtino juzgó así las conversiones de los señores feudales y otros pueblos:

«...Es cierto que todos los señores feudales se interesaron por nuestra santa ley. Por eso no es extraño que si se les enseñan los dogmas cristianos, algunos se conviertan al cristianismo. Porque hasta ahora se han bautizado muchos cristianos escuchando los dogmas cristianos». ${ }^{34}$

\footnotetext{
${ }^{30}$ Carmelo Lisón Tolosana, La Fascinación de la Diferencia. La Adaptación de los Jesuitas al Japón de los Samuráis, 1549-1592, Akal, Madrid, 2005, p. 108.

${ }_{31}$ Takashi Gonor, Nihon Kirisutoyōshi, Yoshikawa, Tokio, 1990, pp. 93-99.

32 Ibidem, pp. 168-169.

${ }^{33}$ Ibidem, p. 100.

34 «Carta de Organtino (14-Febrero-1595)», Iezusukai Nihon Nenpō I-2, p.19.
} 
Aun bajo de la persecución en el período de Edo, el método evangélico consistente en lograr la conversión al cristianismo desde los señores feudales hacia sus súbditos siguió influyendo en las conversiones de los japoneses.

En un informe anual (1599-1601) del Padre Fernando Guerreiro, se informa así de la conversión de los vasallos en dos territorios del señor feudal cristiano Don Konishi Agustiano Yukinaga:

«En el reino de Buzen, que es del territorio de Kai no kami, un hijo de Simean Kanbei, fueron un Padre, con dos hermanos y con algunos catequistas para instalarse e intentar la conversión de aquel reino. Allí hay ya más de dos mil cristianos y algunos de ellos son de los principales de la corte». .35

Se añade sobre el territorio de Chikugo de Kobayakawa Simón Hidenari:

«Después de hacer confesión general, [este señor feudal] decidió hacer todo lo posible para que sus vasallos se hiciesen cristianos. Para esto mando llamar un Padre, con un hermano y algunos catequistas, para que se instalasen en sus tierras, tomando a su cargo el proveerles de todo lo necesario, lo que hizo abundantemente. Causó en todos tanto impacto su conversión, y su buen ejemplo de vida, que en poco más de un mes, se convirtieron a nuestra fe, más de dos mil almas, y se continúa realizando una gran conversión en aquellas tierras». 36

Sobre el territorio señorial Buzen de mismo señor feudal cristiano en la Isla de Kyūshū, escribió:

«Se bautizaron, más de 600 vasallos que en buena parte eran vasallos de Don Sōemon, hermano del Rey Simeón, que era, no solo católico sino también una columna de toda aquella cristiandad de Buzen. Los hermanos edificaron alli el Convento y una iglesia. El Padre confesó a todos los cristianos que están en las diversas partes de aquel reino, que son más de dos mil, los fue a visitar y consolar».37

En la Historia de los Jesuitas $(1605,1607)$, el Padre Bartli dio cuenta de las conversiones de las familias y los parientes de grandes señores feudales, Oda Nobunaga y Toyotomi Hideyoshi:

\footnotetext{
${ }^{35}$ Fernando GuerreIRo, Relación de las Cosas de la Compañía de Jesús en la India y en Japón (16001601), Evora, 1602. B. N. M. R-28459, p. 102; «Informe Anual de la Compañía de Jesús (1599-1601) de Fernando Guerreiro», Kiichi MaTSUDA, 16-17 Seiki Iezusukai Nihon Hōkokusyū I-3, 1988, p.154.

${ }^{36}$ Informe Anual de Fernando Guerrerio, 1602, p. 102.

37 «Informe Anual de Fernando Guerreiro (1599-1601)», Kiichi Matsuda, 16-17 Seiki Iezusukai Nihon Hōkokusȳu 1-III, 1988, p. 209. «Se bautizaron, más de 600 vasallos que en buena parte eran vasallos de Don Sōemon, hermano del Rey Simeón, que era, no solo católico sino también una columna de toda aquella cristiandad de Buzen. Los hermanos edificaron allí el Convento y una iglesia. El Padre confesó a todos los cristianos que están en las diversas partes de aquel reino, que son más de dos mil, los fue a visitar y consolar».
}

Hispania Sacra, LXII

125, enero-junio 2010, 27-42, ISSN: 0018-215-X 
«Fueron bautizados el hijo de Oda Nobunaga que ya alcanzó la mayoría de edad, el hijo de [Kyōgoku Takatsugu que era] el señor feudal de Wakasa, la hija del Toyotomi Hideyoshi, sus familias y vasallos».38

Como se ve, la conversión de los señores feudales continuó siendo una vía importante para extender el cristianismo entre los vasallos de aquéllos.

\section{EL SEGUNDO MÉTODO DE EVANGELIZACIÓN: HACIA LOS PUEBLOS}

En Italia, desde el siglo XIII hasta el XVI se formaron y se desarrolló los grupos de los creyentes cristianos (confraternità) en el proceso de la secularización del cristianismo. Estas cofradías presentan algunas características comunes: son grupos en los que los pueblos participaban voluntariamente, se limita el número de sus miembros, tienen sus obligaciones y los líderes son elegidos entre sus miembros. ${ }^{39}$ Desde 1970 las cofradías se inician investigaciones sobre las cofradías. ${ }^{40}$

Las cofradías europeas surgieron en el ambiente de los monasterios del siglo X y XI en el que insistía en la «Imitatio Christi». ${ }^{41}$ Tuvo influencia de los franciscanos mendicantes del siglo XIII. ${ }^{42}$ El espíritu de las cofradías fue seguido fuertemente por Ignacio de Loyola, que reflejó su espíritu en la fundación de la Compañía de Jesús. ${ }^{43}$ De hecho, se piensa que la palabra «Compañía» contiene el sentido de la cofradía. ${ }^{44}$

R. Weissman explica que «las cofradías proyectaban y trataban de la vida espiritual festiva y de las actividades de la caridad de las comunidades en la zona europea a lo largo de la costa del Mar Mediterráneo. Se fundaron para cuidar la parte importante de la vida espiritual: vida y muerte de los hombres».45

Al sintetizar los resultados recientes de las investigaciones llevadas a cabo en Italia, se puede presentar seis tipos de las cofradías: 46

\footnotetext{
38 «Historia de los Jesuitas $(1605,1607)$ de D. Bartli», Kiichi MatsudA, 16-17 Seiki Iezusukai Nihon Hōkokusȳu 2-I, 1990, p. 6.

${ }^{39}$ Shinzō KaWamura, Kirishitan Shinto Soshiki no Tanjyō to Hen-ȳ̄, Kyōbunkan, Tokio, 2003, pp. 25-26.

40 Ibidem, p. 30

${ }^{41}$ Ibidem, p. 32.

42 Ibidem, p. 35.

43 Ibidem, p. 53.

${ }^{44}$ Ibidem, p. 51.

${ }^{45}$ R. E. F. WeIsSman, Ritual Brotherhood in Renaissance Florence, Academic Press, New York y London, 1982, p. 9; Shinzô Kawamura, Kirishitan Shinto Soshiki no Tanjyô to Hen-yô, Kyôbunkan, Tokio, 2003, p. 55.

${ }^{46}$ Shinzō KaWamura, Kirishitan Shinto Soshiki no Tanjyō to Hen-yō, Kyōbunkan, Tokio, 2003, p. 61.
} 
$1^{\circ}$ - Cofradía de la gente de los azotes (Disciplinati)

$2^{\circ}$ - Cofradía de la misericordia,

$3^{\circ}$ - Cofradía de devoción (Devotio)

$4^{\circ}$ - Cofradía de las laudes (Laudesi)

$5^{\circ}$ - Cofradía de los chicos

$6^{\circ}$ - Cofradía de los profesionales

En el proceso de la evangelización se organizaron también en Japón diversas cofradías. Estas tuvieron mucha importancia en la vida de los cristianos japoneses. Los japoneses las llamaron «confrarías», a partir del término portugués. Cabe presumir que los jesuitas las introdujeron en tierras niponas. ¿Cómo era y donde se establecieron? La respuesta se basa en documentos de los jesuitas.

Yamaguchi era un territorio señorial de Ōuchi Yoshitaka. En 1551, Francisco Javier empezó a evangelizar en esta ciudad de Honsyū consiguiendo el permiso de Ouchi Yoshitaka. Al leer documentos, se puede advertir cómo grupos cristianos japoneses llevaron a cabo obras de caridad bajo de la dirección de los jesuitas.

En los días que fue escrita la Carta de Pedro de Alcaçova (1522-1579), se sucedían multitud de guerras en Yamaguchi, y la hambruna hacía estragos en la población. En esta situación, los grupos de cristianos japoneses hicieron acopio de arroces para su distribución entre los pobres. ${ }^{47}$

Cosme de Torres relató otro caso que puede servir de ejemplo de la labor de las agrupaciones cristianas o cofradías en su Carta de 1554. Los cristianos, Ambrogio y su mujer, empezaron a repartir alimentos. Al principio, se repartieron mensualmente. Luego, cuatro veces, gracias a ayuda de unos grupos de cristianos. 48

De esta manera, en estos días surgió la forma original de las cofradías en la ciudad de Yamaguchi. Es una prueba de la introducción de la cofradía tradicional europea en Japón.

47 «Carta de Pedro de Alcaçova (3-1554)». J. RuIZ DE Medina, Monumenta Histórica Japoniae II, Institutum Historicum Societatis, Rome, 1990, pp. 420 y 422.

48 «Carta de Cosme de Torres (10-1554)». J. RuIz DE Medina, Monumenta Histórica Japoniae II, Institutum Historicum Societatis, Rome, 1990, pp. 461.

Hispania Sacra, LXII

125, enero-junio 2010, 27-42, ISSN: 0018-215-X 


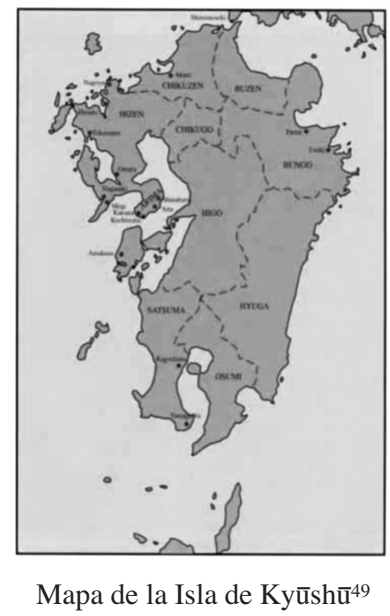

El Padre jesuita Bartazar Gago comenzó la evangelización de esta ciudad Hirado, isla de Kyūshū. Según la documentación llegada a nuestros días, en esta ciudad el Padre Garpar Vilela (1526-1572) jugó un papel importante para el nacimiento de la cofradía.

Poco después de iniciarse la evangelización de esta ciudad, el señor feudal Matsuura Takanobu empezó a perseguir el cristianismo. Desterró a los Padres, y la comunidad de los cristianos de Hirado quedó aislada. En este tiempo, Gaspar Vilela presentó un proyecto. Conforme a é, eligió siete diáconos japoneses para suplir a los Padres desterrados, encargándoles la convocatoria de los cristianos a la misa y el entierro de los muertos. Se nombró a estos diáconos como «Majordomos». Y se implantó este sistema en toda la ciudad de Hirado. ${ }^{50}$ Podemos apreciar cómo estos grupos presentan los rasgos distintivos propios de la cofradía de misericordia. Según la carta de Juan Hernández de 1565, se puede deducir que estas cofradías de misericordia siguieron funcionando y arraigando en Hirado..$^{51}$

La evangelización del territorio de Bungo la comenzó Bartazar Gago. Luego vinieron Cosme de Torres y Juan Fernández. La evangelización tuvo como base

\footnotetext{
${ }^{49}$ Carmelo Lisón Tolosana, La Fascinación de la Diferencia. La Adaptación de los Jesuitas al Japón de los Samuráis, 1549-1592, Akal, Madrid, 2005, p.109.

50 «Cartas que os Padres e Irmão da Companhia de Iesus», J. RuIZ DE Medina, Monumenta Histórica Japoniae I, pp. 318v-319; Shinzō Kawamura, Kirishitan Shinto Soshiki no Tanjyō to Hen-yō, Kyōbunkan, Tokio, 2003, p. 122.

${ }^{51}$ Shinzō Kawamura, Kirishitan Shinto Soshiki no Tanjyō to Hen-yō, Kyōbunkan, Tokio, 2003, pp. 124-125.
} 
Funai y en Niujima. La comunidad cristiana de Bungo se estableció en el 1550, y continuó después de 1670 cuando estaba prohibido el cristianismo por el shōgunato. Por eso esta zona tendrá una larga tradición cristiana. Aproximadamente en 1555 el Padre Cosme de Torres organizó también la cofradía de misericordia en Bungo. Se abrió entonces un hospital en Funai. Doce cristianos fueron elegidos como «Majordomos». Según la Carta de Juan Fernández, la misericordia de Bungo eligió los líderes con el método democrático, y respetó su fe. Además, Juan Fernández indicó que en los estatutos se determinó la elección de los líderes. ${ }^{52}$ La cofradía celebraba reuniones periódicas.

«Los domingos a las tardes tienen costumbre de se ajuntar em casa de uno dellos, mudándose todos los domingos asta que pase por todos. Y ahi se ejercitan tres obras de misericordia. La primera, que se resumen la predicación oída... La $2^{\circ}$ es que cada uno da una caixa, que serán dos maravidís, la qual cosa sirve para enterrar los puebres... La $3^{\circ}$ es que el duenho de la casa haze un banquete a todos los que se ajuntan...».53

Igual que la cofradía de Florencia, la de Bungo impulsó activamente los entierros de los muertos según el modo occidental. En la Carta de Juan Fernández, los describe así en este fragmento:

"Los enterramientos de los christianos difuntos [de Funai] causan mucha edificación, assí a gentiles como a christianos, de lo qual tiene cargo el charíssimo Duarte de Sillva. Emterram todos, assí pobres como ricos, mui sumptuosamente. Porque a los pobres ajuda la casa de Misericordia». ${ }^{4}$

También, la cofradía de Bungo hizo un notable esfuerzo para la educación de los niños. El Padre Juan Fernández explica el estudio de catecismo por los niños en estos términos:

«El charíssimo Gilherme, afuera las letiones que tiene continuas de lengua de Japón, enseña la doctrina christiana a los ninhos».55

52 «Carta de Juan Fernández». J. RuIz DE Medina, Monumenta Histórica Japoniae II, Institutum Historicum Societatis, Rome, 1990, p. 417.

53 «Carta de Juan Fernández (8-10-1561)». J. RuIz DE Medina, Monumenta Histórica Japoniae III, Institutum Historicum Societatis, Rome, 1990, pp. 421-422.

54 «Carta de Juan Fernánde». J. RUIZ DE Medina, Monumenta Histórica Japoniae III, Institutum Historicum Societatis, Rome, 1990, p. 430.

55 «Carta de Juan Fernández (8-10-1561)». J. Ruiz De Medina, Monumenta Histórica Japoniae III, Institutum Historicum Societatis, Rome, 1990, p. 409.

Hispania Sacra, LXII

125, enero-junio 2010, 27-42, ISSN: 0018-215-X 


\section{DESARROLLO DE LAS COFRADÍA EN JAPÓN}

Como modelo de desarrollo de las cofradías, tomamos el ejemplo de la Nagsaki, que fue un modelo para las otras. A partir de 1580 fue el centro de la Iglesia de la ciudad. En 1583, el Padre Luis Frois presentó un informe sobre ella. Tenía una preciosa capilla y era administrada por algunos cristianos. Su labor principal era ayudar a los pobres, a las viudas y a los enfermos. El 1585, el Padre Luis Frois informaba así:

«Hace dos años informó a prepósito que establecíamos una cofradía en Nagasaki imitando de la de misericordia de Portugal. Los miembros de esta cofradía eran 100 hermanos (irmãos) y un jefe (provedor). Adornamos suficientemente a nuestra capilla. Importamos el bandeja y el compromiso igual que los portugueses tenían en la cofradía de Macao. Con este compromiso, administramos nuestra cofradía. Se decidió que el 2 de Julio en el que Santa María visitó a Santa Elizabeth era una fiesta. En este día, hubo gran ceremonia, e hicimos varias funerales y asuntos administrativos. $Y$ recaudamos ofrenda en la ciudad para los pobres. Se hizo nuestra actividad igual que en Europa».56

Los miembros de la cofradía de Nagasaki también cuidaban de los leprosos.

«Aunque los miembros de la cofradía de Nagasaki eran pobres, les interesaban mucho las obras de caridad. Por lo tanto, construyeron una casa para los leprosos. Siempre, dos personas cuidaban esta casa. Los gentiles odiaban y echaban a estos leprosos. Por lo tanto, el cuidar a ellos es un trabajo horrible para los japoneses. Sin embargo, esta casa era muy limpia. Y los leprosos no faltaban nada, porque los miembros de la cofradía solía donar y dar comidas para ellos. Por eso, los leprosos se sorprendieron mucho».57

Había otras cofradías similares Se llamaban «misericordia». Desde la etapa de su surgimiento hasta la de su desarrollo, las cofradías japonesas tenían principalmente la función del desarrollo de las obras de «misericordia».58 Lógicamente, al ser recientes en la fe, los Padres jesuitas intervenían en la administración de esos bienes más que en los países europeos. ${ }^{59}$

En el período de la persecución contra los cristianos que empezó con Toyotomi Hideyoshi y continuó con Tokugawa Ieyasu, las cofradías japonesas tuvieron una enorme importancia. Con persecución fueron desterrados muchos Padres europeos, y las cofradías fueron la forma en que los cristianos pudieron mantener la fe por sí mismos. En esta situación, las cofradías se convirtieron en el centro del cristianismo en muchas regiones de Japón.

\footnotetext{
56 Kiichi Matsuda, 16-17 Seiki Iezusukai Nihon Hōkokusyū III-6, Dôhôsha, Tokio, p. 305.

${ }^{57}$ Kiichi Matsuda, Momota KawasaKi, Nihonshi, Chūōkōronsha, Tokio, 1975, p.263.

58 Shinzō Kawamura, Kirishitan Shinto Soshiki no Tanjyō to Hen-yō, Kyōbunkan, Tokio, 2003,

${ }^{59}$ Ibidem, p. 125.
} p. 87. 
Sus miembros siguieron realizando obras de caridad: atendieron a los enfermos y pobres, fomentaron la educación y el estudio, sostuvieron la iglesia y preservaron sus ritos religiosos en funerales y fiestas, entre otros. Hubo las Cofradías de Martirio, de Santa María y de Jesús, en la localidad de Arima, organizadas por los jesuitas. Clandestino, los cristianos continuaron sus actividades, pese a la persecución. ${ }^{60}$

En resumen, hemos visto la continuidad de la mentalidad medieval europea en la misión en Japón. Primero, procurando la conversión de los señores feudales para con ello facilitar el bautismo de sus vasallos. Luego, difusión del cristianismo en contacto directo el pueblo. Los jesuitas observaron los distintos estamentos sociales. Todos los jesuitas procedían de Portugal y de España. Por lo tanto, es plausible pensar que su análisis de la sociedad japonesa partiendo del modelo ibérico. La conciencia medieval de clases formada por la Reconquista y las asambleas representativas influirían así en la evangelización en Japón.

En la evangelización directa del pueblo, introdujeron el sistema de cofradías desarrollado en los países del Mediterráneo. Las japonesas de esta época, pertenecían el tipo de «misericordia». ${ }^{61}$ Através de las obras de caridad reforzaron la confraternidad entre sus miembros, y desarrollaron la evangelización, llegando a ser los centros de la evangelización en Japón. Parece que los jesuitas intervenían en su administración más que lo solía hacerse en los países europeos. ${ }^{62}$

\footnotetext{
60 Takashi DonoI, Nihon Kirisutokyōshi, Yosyikawa, Tokio, 1990, pp. 207-209.

${ }^{61}$ Cfr. Shinzō Kawamura, Kirishitan Shinto Soshiki no Tanjyō to Hen-yō, Kyōbunkan, Tokio, 2003, p.87.

${ }^{62}$ Ibidem, p. 125.

Hispania Sacra, LXII

125, enero-junio 2010, 27-42, ISSN: 0018-215-X
} 